\title{
Movements of reef fishes across marine reserve boundaries: effects of manipulating a density gradient
}

\author{
D. Zeller ${ }^{1,2, *}$, S. L. Stoute ${ }^{1}$, G. R. Russ ${ }^{1}$ \\ ${ }^{1}$ School of Marine Biology and Aquaculture, James Cook University, Townsville, Queensland 4811, Australia \\ ${ }^{2}$ Present address: Fisheries Centre, 2204 Main Mall, University of British Columbia, Vancouver, British Columbia V6T 1Z4, \\ Canada
}

\begin{abstract}
Marine reserves should display net export of biomass if they are to be of use in fisheries management. We assessed experimentally the export of fish biomass ('spillover') from 2 marine reserves on the Great Barrier Reef. Using the mark-recapture technique with traps, and hook-andline fishing, movements of serranids, lutjanids and lethrinids were monitored at 2 experimental and 2 control sites. Experimental sites were bisected by reserve boundaries into 'zones' open and closed to fishing. Control sites were protected from fishing, with an arbitrary boundary creating 2 equal zones. Between 1997 and 1999, 1374 individuals were externally tagged, and during 1999 densities were manipulated twice. Underwater visual census (UVC) surveys revealed pre-manipulation density gradients between zones that were weak at real boundaries, and stronger at the arbitrary control boundaries. Movements were highly localized, with over $60 \%$ of recaptures being made within the $50 \times 30 \mathrm{~m}$ block of initial capture. The mean distances moved differed between the 3 species with the highest recapture rates: Plectropomus leopardus (Serranidae) moved distances $>100 \mathrm{~m}$, Lutjanus carponotatus (Lutjanidae) occasionally moved over $50 \mathrm{~m}$, while Cephalopholis cyanostigma (Serranidae) was predominantly caught within the block of initial capture. Movements across real or control boundaries were rare. Twice in 1999, fish densities in zones open to fishing at the experimental sites were reduced by spearfishing (by 61 to $64 \%$ and 57 to $83 \%$, respectively). UVC revealed density gradients at the experimental boundaries and no changes at non-manipulated control sites. There was no evidence of experimentally induced directional movements, using traps or hook-and-line sampling; however, 3 species (C. cyanostigma, L. carponotatus, L. quinquelineatus) did show a propensity for increased movements. Detection of spillover requires powerful sampling designs incorporating strong density gradients across large numbers of reserve boundaries.
\end{abstract}

KEY WORDS: Marine reserves · Spillover · Fisheries management · Coral reefs · Experiment · Movements · Tagging

\section{INTRODUCTION}

Conventional fisheries management, based mainly on single-species stock-assessment models and catchand-effort regulations, has proved to be largely ineffective and unable to account for the complexities of most coral reef fisheries (Russ 1991, Roberts \& Polunin 1993). Enforcing conventional management measures has also proved difficult, as most coral reef fisheries exist in developing countries where the demand for fishery yields is extraordinarily high (Russ 1991).
No-take marine protected areas, or marine fisheries reserves, have been promoted extensively as a viable alternative to coral reef fisheries management, and have the capacity to deal with problems that are not effectively addressed by traditional management measures (Roberts \& Polunin 1993, Bohnsack 1998a). Marine reserves are thought to represent a more simple, holistic approach to coral reef fisheries management, and may be implemented and enforced independent of detailed stock assessments and biological information (PDT 1990). An increasing number of fish- 
eries scientists have advocated their use as a fisheries management tool (Alcala \& Russ 1990, Roberts \& Polunin 1993, Bohnsack 1998a). However, the extent to which marine reserves actually meet such expectations is largely unknown, due to the paucity of well-designed studies that quantitatively assess the suitability of marine reserves for fisheries management (Russ 2002).

One of the major objectives of fisheries reserves is to maintain a critical spawning-stock biomass, and to subsequently sustain, or potentially enhance, adjacent fisheries through the net export of fish biomass (Alcala \& Russ 1990). Such export may occur through enhanced recruitment to non-reserve areas via larval dispersal (recruitment effect), or through an increase in the propensity of post-settlement fishes to move across reserve boundaries into adjacent fisheries (spillover effect: Russ \& Alcala 1996a, McClanahan \& Mangi 2000). For marine reserves to be an effective tool in fisheries management, biomass export in the long term should at least compensate for the inevitable loss of fishing area when a reserve is established. Demonstrating to local fishers, especially in developing countries, that their catches stand to benefit from the establishment of a marine reserve is likely to be of tremendous significance to the implementation of marine reserves (Russ \& Alcala 1996a).

Inherent difficulties in tracking the fate of larvae have, at present, precluded any unequivocal demonstration of a recruitment effect of marine reserves (Rowley 1994, Russ 2002), but benefits to fisheries as a result of enhanced recruitment supply could be expected on a regional scale, as larvae have the potential to travel 10 s to 100 s of kilometres (Leis 1991). In contrast, the ability to mark post-settlement fishes with internal or external tags provides a means by which the movements of these fishes may be monitored, and the potential for spillover effects assessed. Although there is some evidence suggesting that spillover events occur (Alcala \& Russ 1990, Russ \& Alcala 1996a, McClanahan \& Mangi 2000, Roberts et al. 2001), most studies fail to discriminate spillover from natural variability in movement patterns, due to poor experimental designs and tagging strategies, coupled with a paucity of information describing fundamental movement patterns (Polacheck 1990, Rowley 1994, Russ 2002).

The potential contribution of recruitment and postsettlement movements to biomass export from marine reserves has been simulated repeatedly using fishery population models (Beverton \& Holt 1957, Polacheck 1990, DeMartini 1993, Russ et al. 1993, Attwood \& Bennett 1995) and spatial ecosystem models (Walters et al. 1999). Together, these models demonstrate the potential for a build-up of spawning-stock biomass per recruit within reserve areas, and that moderate increases in yield per recruit may be achievable when high levels of fishing mortality outside reserve areas coincide with relatively high rates of transfer of postsettlement fish biomass across reserve boundaries (Polacheck 1990, DeMartini 1993, Russ et al. 1993). In turn, transfer rates are probably regulated by the mobility of the target species, and the size and shape of the reserve area (Polacheck 1990, DeMartini 1993).

The propensity for post-settlement fishes to relocate to areas outside marine reserves is thought to be largely dependent on increases in fish density within the reserve (Rakitin \& Kramer 1996, Bohnsack 1998a). Following an accumulation of biomass, random flux rates or density-dependent processes may result in net movement (net flux) of fishes into adjacent habitats (Chapman \& Kramer 1999, Russ 2002). Theoretical modelling has recognised the role of fish movements between reserve and non-reserve habitats to be important to the functioning of marine reserves (Chapman \& Kramer 1999). Given the potential importance of such movements, the current evidence for spillover, albeit indirect, has typically been derived from studies monitoring catch rates and densities within and surrounding marine reserves (Alcala \& Russ 1990, Yamasaki \& Kuwahara 1990, Rakitin \& Kramer 1996, Russ \& Alcala 1996a, Chapman \& Kramer 1999, McClanahan \& Mangi 2000, Roberts et al. 2001). A few tagging studies have attempted to directly measure flux rates of reef fishes across reserve boundaries (Funicelli et al. 1989, Beinssen \& Beinssen 1991, Attwood \& Bennett 1994, Zeller \& Russ 1998).

Although some studies have quantified movements of reef fishes across reserve boundaries through markrelease-recapture programmes, the degree to which these movements represent a response to protective management is often difficult to assess (Funicelli et al. 1989, Beinssen \& Beinssen 1991, Rakitin \& Kramer 1996). A major problem associated with such tagging studies is that the movement patterns of a single species are often measured at 1 reserve location, with no control for the natural movement patterns of the species in that area. Several studies have suggested that the potential for fishes to move between habitats or relocate to areas beyond their home range is influenced by differences in habitat quality and the presence of physical barriers (Buechner 1987, Chapman \& Kramer 1999). For example, movements may be facilitated across areas of contiguous or favourable habitats, but may be restricted by large areas of sandy substratum with low structural complexity (Barrett 1995). In addition, the propensity for individuals to cross physical barriers may depend on the mobility and behavioural patterns of the species involved (Roberts \& Polunin 1991). Consequently, it is imperative that studies attempting to quantify spillover examine a combination of species in multiple reserve and control locations. 
Many tagging studies are also compromised by deficiencies in their sampling protocol, such as the failure to tag individuals in both protected and unprotected sites (Attwood \& Bennett 1994), and the lack of equal tagging and recapture effort within fished and unfished areas (Davis \& Dodrill 1989). Without evenly distributing tagging and recapture effort across protected and non-protected habitats, the ability to determine net export is lost. Detecting spillover also requires that the scale at which movements may be detected by the sampling design corresponds to the scale at which movements actually occur. Many reef fishes have been shown to move over distances ranging from 10s to 100s of metres (Roberts \& Polunin 1991, Samoilys 1997, Zeller 1997, 2002, Zeller \& Russ 1998). However, the resolution of movement studies has often ranged from $500 \mathrm{~m}$ to some kilometres (Beinssen \& Beinssen 1991, Attwood \& Bennett 1994, Chapman \& Kramer 1999). In such cases, movements may not be detected.

The present study used mark-release-recapture sampling with 2 capture techniques, trapping, and hookand-line fishing, to quantify the potential for spillover. We applied a before-after-control-impact (BACI) design to examine the effects of experimentally manipulating density at 2 reserve boundaries on the short-term movement patterns of reef fishes. The specific aim of the project was to determine if there were net export of post-settlement fishes from the marine reserves and to examine the effects of manipulating the density on fish

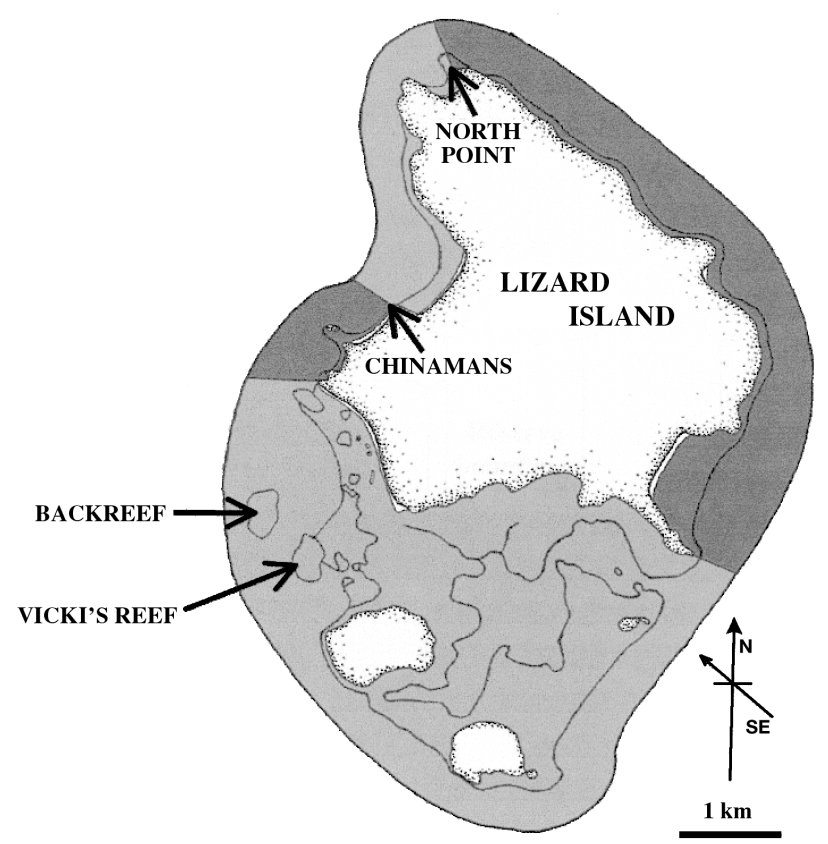

Fig. 1. Map of Lizard Island showing study sites and marine park management zoning patterns around the island. Light shading indicates areas permanently closed to fishing (marine reserves), darker shading areas open to fishing movement. Movements at the 2 manipulated boundaries were compared to those at 2 control sites. The primary target species were the Serranidae (groupers), Lutjanidae (snappers) and Lethrinidae (emperors). Together, these 3 families comprise the majority of the commercial and recreational catch on the Great Barrier Reef, and are also targeted by many coral reef fisheries (Russ 1991, Mapstone et al. 1996).

\section{MATERIALS AND METHODS}

Study site. The study was conducted between 1997 and 1999 at Lizard Island $\left(14^{\circ} 40^{\prime} \mathrm{S}, 145^{\circ} 28^{\prime} \mathrm{E}\right)$, a high continental island with extensive coral reef formation (Choat \& Bellwood 1985) on the Great Barrier Reef (GBR), Australia. We utilized 4 study sites, each covering $300 \times 30 \mathrm{~m}$ of reef habitat, established on the leeward side of Lizard Island in 1997 (Fig. 1). The management zoning plan for Lizard Island (containing areas open and closed to fishing) permitted the establishment of these sampling sites on both reserve boundaries and in areas completely protected from fishing. Two experimental sites, Chinamans and North Point, were situated in marine reserve boundaries (Fig. 1). Each experimental site extended $150 \mathrm{~m}$ on either side of the boundary into zones open to fishing and zones closed to all fishing, respectively (Fig. 2). The positioning of these sites in relation to established marine reserve boundaries permitted the quantification of movements, or 'flux' rates, of reef fishes across those boundaries. The reserve boundary at Chinamans had been established for $9 \mathrm{yr}$ (since 1988), while the boundary at North Point was established in 1996. Two control sites, Vicki's Reef and Backreef, were located fully within zones closed to fishing (Fig. 1). Arbitrary boundaries were defined within these control sites such that each site was artificially divided into two $150 \times 30 \mathrm{~m}$ zones in the same way as the 2 experimental sites in true marine reserve boundaries (Fig. 2).

Each site was subdivided into 6 equal $50 \times 30 \mathrm{~m}$ blocks (Fig. 2). The experimental site at Chinamans was an exception, being restricted to only 5 equal $50 \times 30 \mathrm{~m}$ blocks, as the reef only extended $100 \mathrm{~m}$ into the zone closed to fishing, where the benthic reef habitat changed to sand. To minimize any potential bias associated with habitat variability, sampling was restricted to the reef habitat (Carpenter et al. 1981). Prior to sampling, individual $50 \times 30 \mathrm{~m}$ blocks within each site were delineated by surface buoys to facilitate sampling effort (Fig. 2). Antillean Z-traps, and standard hook-and-line gears were used as methods of capture/recapture to measure movements; underwater visual census (UVC) was used before and after each manipulation as an independent estimate of density. 


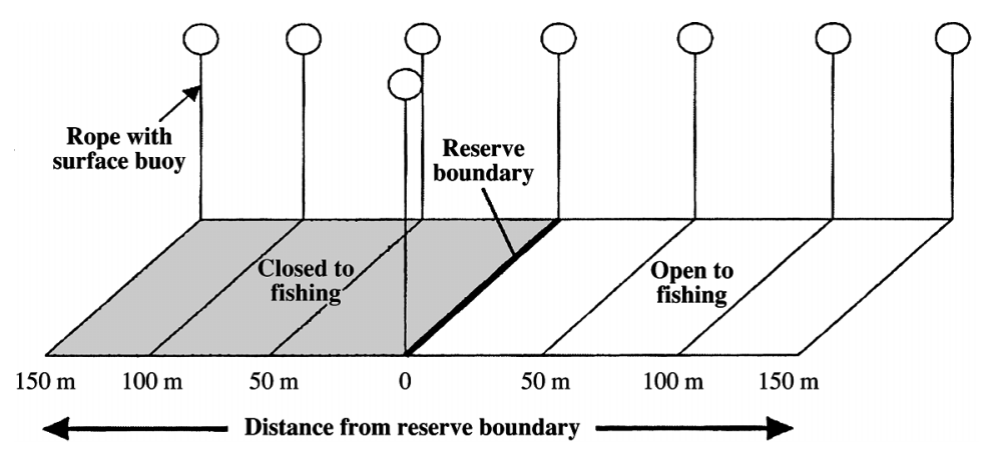

Fig. 2. Diagrammatic representation of a $300 \times 30 \mathrm{~m}$ sampling site (distances not to scale). Distinction between zones (open vs closed) was arbitrarily allocated at the control sites, Backreef and Vicki's Reef. Surface floats defined each block to facilitate trapping and fishing effort allocation

Antillean Z-traps. The Antillean Z-traps were based on a design used in the Caribbean Sea (Munro 1983) and on the Great Barrier Reef (Davies 1995). Each trap had an area of $1.91 \mathrm{~m}^{2}$ and a volume of $1.13 \mathrm{~m}^{3}$, and consisted of a steel frame (welded $8 \mathrm{~mm}$ mild steel bars) enclosed with square galvanized mesh $(12.5 \mathrm{~mm}$ square, 0.9 gauge). Two elliptical funnels were located at the apex of each diagonal concave face on either side of the trap. The funnels were straight, with an outer aperture of $420 \times 200 \mathrm{~mm}$ and an inner aperture of $250 \times 150 \mathrm{~mm}$. Each trap was attached to a surface buoy with a $15 \mathrm{~m}$ length of $30 \mathrm{~mm}$ rope, facilitating retrieval from a dinghy. Before each field trip all trap frames were covered with mesh that had been conditioned in seawater for $2 \mathrm{wk}$, as 'conditioned' mesh fishes more effectively (Newman 1990).

Where possible, traps were positioned flat and stable on the substrate. An underwater viewing scope was used to ensure that the traps were properly orientated. If the trap was incorrectly set (e.g. tilted) it was either reset from the boat or re-positioned underwater by a free diver. Traps were baited with approximately $450 \mathrm{~g}$ of frozen American pilchard Sardinops sajax in bait canisters constructed from PVC pipes, $250 \mathrm{~mm}$ long (90 mm diameter), with four $20 \mathrm{~mm}$ horizontal slits on either side and removable caps at each end. Canisters were suspended by a wire from the centre of the top mesh panel of each trap. Any bait remaining from previous trapping sessions was discarded.

Sites were sampled using 6 traps, with a single trap allocated to each $50 \times 30 \mathrm{~m}$ block ( 5 traps only were used at the Chinamans site). Blocks within each site were sampled simultaneously. A sampling replicate (soak) was defined as the time interval (24 h) between trap deployment and subsequent hauling. (Davies 1989) showed that trap catches for a number of reef fishes reach an asymptote after 2 to 3 d soak-time. Thus, a $24 \mathrm{~h}$ period of soak ensured that the traps did not satu- rate. All traps were set within the central area of each block, making the distance between adjacent traps approximately $50 \mathrm{~m}$. At this distance it has been shown that the fields of capture of adjacent traps should not overlap (Eggers et al. 1982). Thus, the catch rates of adjacent traps were assumed to be independent. Hence, the resolution of movement detected in this study was on the scale of $50 \mathrm{~m}$, and the maximum detectable distance moved was $250 \mathrm{~m}$. Given the small spatial scale of the tagging sites and a minimum time between potential recaptures of $24 \mathrm{~h}$, fishes had the capacity to move among all blocks within a site between consecutive soaks (Zeller 1997). Consequently, all movements were considered to be independent, including those recorded for multiple recaptures.

Hook-and-line fishing. Hook-and-line fishing was conducted with standard handline fishing techniques used by commercial reef fishers on the Great Barrier Reef (Mapstone et al. 1996). A single 7/0 hook on an $80 \mathrm{lb}(36 \mathrm{~kg})$ line was used, baited with half a frozen American pilchard ( 30 g). Fishing was carried out from an anchored $4.3 \mathrm{~m}$ aluminium dinghy, with 2 fishers each using a single handline. Line-fishing effort was concentrated in the centre of each block. Fishing effort was standardized within and among sites by allocating 20 min of fishing time (hook in the water) to each block. Thus, a single replicate consisted of a total fishing effort per block of 40 hook-and-line minutes (i.e. 2 fishers at $20 \mathrm{~min}$ each). All blocks within a site were fished on the same day in a random manner to reduce any consistent bait-attraction effect between blocks. In addition, hook-and-line fishing and trapping were not conducted simultaneously at the same sites to ensure that the sampling gears fished independently.

Tagging. All fishes caught were identified to species (Carpenter \& Allen 1989, Randall et al. 1997), and fork length of all target species (serranids, lutjanids and lethrinids) were recorded to the nearest millimetre. Fish were examined for T-bar anchor tags (Hallprint ${ }^{\circledR}$ ) and tag numbers were recorded. Untagged fishes were tagged in the dorsal musculature between pterygiophores, approximately 5 to $10 \mathrm{~mm}$ below the base of the dorsal fin. Tags were visually obvious (yellow), individually coded with a 5-digit number, and provided with a contact telephone number.

Underwater visual census. In conjunction with the fisheries sampling techniques outlined above, UVC surveys were conducted by 2 of the authors (D.Z. and G.R.R). Each site was subdivided into six $300 \times 5 \mathrm{~m}$ lanes. Subsurface floats defined the sides of these lanes, and boundaries between blocks were marked with rope. The 2 observers simultaneously censused the length of 2 adjacent lanes. Three full-length (300 m) 
swims of the site were conducted to complete 1 census. Each observer recorded abundance and length (estimated to the nearest $5 \mathrm{~cm}$ ) of all serranids, lutjanids and lethrinids. The method of Bell et al. (1985) was used to train observers in size estimation. Both tagged and untagged individuals were recorded. UVC data was used both to provide a fisheries-independent estimate of densities before and after each manipulation, and also to determine whether manipulations affected the density gradients at the reserve boundaries.

Experimental manipulation. The first $2 \mathrm{yr}$ of the study (1997 and 1998) comprised a baseline study, with no density manipulations (D.Z. \& G.R.R. unpubl. data). In 1999, experimental manipulations were conducted during 2 periods (April-May and July-August). The experimental design was analogous to a BACI-type environmental impact assessment model (Underwood 1994). Within each period the sampling protocol was the same, with 3 or 4 replicate trap, and hook-and-line samples being taken at all 4 sites before and after each manipulation. Strong wind conditions permitted only 1 or 2 replicates of hook-and-line fishing samples to be completed before and after the first manipulation.

Manipulation consisted of using spears to remove individuals and thereby reducing the densities of target species in the zones open to fishing at the experimental sites at Chinamans and North Point. All removals were performed under Great Barrier Reef Marine Park Authority research permit guidelines. Serranids, lutjanids, and lethrinids of all sizes were targeted. Fish densities were not manipulated at the 2 control sites. During each sampling period, $2 \mathrm{~h}$ of spearing effort by each of 2 spearfishers was allocated to each $50 \times 30 \mathrm{~m}$ block in the open zone within each of the 2 experimental sites (total spearfishing effort per block $=4 \mathrm{~h}$ ), for a total of 12 spearfishing hours per site. Effort per site was subdivided into 4 separate sessions conducted equally over $4 \mathrm{~d}$. Blocks within each site were fished (speared) consecutively each day, in an order that alternated between sessions to account for any bias in spearing effort with time. The time-scale used for the manipulation was thought to be sufficient, as catch rates were significantly reduced by the last day. Additional spearing would probably have contributed little to the removal of fishes from these zones.

The potential for spillover (net export of adult fishes) from reserve zones was assessed by quantifying the flux rates of target species across the established reserve boundaries at the 2 experimental sites before and after manipulation. To examine the effects of manipulating density at the experimental sites relative to the direction and rate of boundary crossings, comparisons were made with movements across the arbitrarily defined boundaries at the 2 control sites where densities were not manipulated. These arbitrary bound- aries at the control sites were established under the assumption that the propensity for fishes to move between the two $150 \times 30 \mathrm{~m}$ zones within each control site would not change through time. The controls therefore provided an indication of temporal variability of natural movement patterns.

Data analysis. Movements across each $50 \mathrm{~m}$ increment were expressed as a proportion of the total recaptures within each site, and differences in the distribution of distances moved for the 4 sites were analyzed using chi-square homogeneity tests. Because of the limited frequency of movements $>100 \mathrm{~m}$, movements $\geq 100 \mathrm{~m}$ were pooled to ensure that the minimum expected frequency was $>1$, and that no more than $20 \%$ of expected frequencies were $<5$ (Cochran 1954). Furthermore, to examine whether distances moved within sites were consistent between gear types, a separate chi-square homogeneity test was performed for each gear type. The distribution of distances moved by the 3 species with the highest recapture rates (coral trout Plectropomus leopardus, blue-spot rock cod Cephalopholis cyanostigma and stripey Lutjanus carponotatus) were compared among sites by a chisquare homogeneity test.

For individuals whose recapture history could be traced back to their time and location of first capture (between 1997 and 1999), distances moved were compared to time at liberty (i.e. time since last recapture). No formal analysis was undertaken for associations between time at liberty and distance moved, as there was no indication of a relationship between the 2 variables.

To provide fishing-gear-independent estimates of density, UVC estimates (log-transformed) were compared before and after each manipulation at each site using a 4 -factor ANOVA, treating Trip (Manipulations 1 and 2), Site (experimental and control sites), Zone (open and closed to fishing) and Time (before/after each manipulation) as a fully factorial design.

To assess the effects of the density manipulation at the 2 experimental sites on distances moved, a chisquare homogeneity test was performed on the total number of movements detected before and after manipulation at each site. The 2 manipulations carried out at 2 different times (April-May and July-August) were analyzed separately.

Comparisons were made between the direction and frequency of boundary crossings recorded before and after each manipulation at all sites. Distances moved to cross a boundary were also compared among sites to determine if the majority of crossings were from particular areas within sites. The frequency of boundary crossings was relatively low at all sites, and thus prevented any statistical comparison of rates and direction of boundary crossings between species. 
Table 1. Number of fishes recaptured at each site during 1999. Number of fishes tagged between 1997 and 1999 are also indicated for those species for which recaptures were recorded. A total of 1374 fish from 31 species were tagged, with 72 individuals belonging to species that were not recaptured. Lethrinus sp. 2 is an undescribed species of Lethrinus (Carpenter \& Allen 1989). Total number recaptured $=347$

\begin{tabular}{|c|c|c|c|c|c|}
\hline Taxon & $\begin{array}{c}\text { No. } \\
\text { tagged }\end{array}$ & $\begin{array}{l}\text { Experin } \\
\text { China- } \\
\text { mans }\end{array}$ & $\begin{array}{c}\text { mental } \\
\text { North } \\
\text { Point }\end{array}$ & $\begin{array}{l}\text { Cor } \\
\text { Back- } \\
\text { reef }\end{array}$ & $\begin{array}{l}\text { atrol } \\
\text { Vicki's } \\
\text { Reef }\end{array}$ \\
\hline \multicolumn{6}{|l|}{ Serranidae } \\
\hline Plectropomus leopardus & 287 & 2 & 4 & 51 & 59 \\
\hline Cephalopholis cyanostigma & 225 & 39 & 18 & 23 & 4 \\
\hline Epinephelus merra & 29 & 0 & 3 & 0 & 6 \\
\hline E. quoyanus & 19 & 9 & 0 & 0 & 0 \\
\hline E. maculatus & 12 & 6 & 0 & 0 & 1 \\
\hline C. miniata & 2 & 2 & 0 & 0 & 0 \\
\hline E. ongus & 15 & 1 & 0 & 1 & 0 \\
\hline E. cyanopodus & 4 & 1 & 0 & 0 & 0 \\
\hline \multicolumn{6}{|l|}{ Lutjanidae } \\
\hline Lutjanus carponotatus & 142 & 37 & 4 & 11 & 3 \\
\hline L. bohar & 71 & 0 & 7 & 3 & 4 \\
\hline L. quinquelineatus & 45 & 0 & 10 & 0 & 0 \\
\hline L. gibbus & 16 & 0 & 1 & 0 & 0 \\
\hline L. russelli & 24 & 0 & 0 & 0 & 1 \\
\hline \multicolumn{6}{|l|}{ Lethrinidae } \\
\hline Lethrinus atkinsoni & 119 & 1 & 0 & 9 & 10 \\
\hline Lethrinus sp. 2 & 234 & 0 & 12 & 1 & 0 \\
\hline L. nebulosus & 51 & 2 & 0 & 0 & 0 \\
\hline L. obsoletus & 7 & 0 & 0 & 0 & 1 \\
\hline Total & 1302 & 100 & 59 & 99 & 89 \\
\hline
\end{tabular}

counted for $95 \%$ of recaptures, while at Vicki's Reef 2 species, P. leopardus and $L$. atkinsoni, dominated recaptures $(77 \%)$. At Chinamans, $76 \%$ of all recaptures consisted of C. cyanostigma and Lutjanus carponotatus, while at North Point, recaptures were dominated (67\%) by C. cyanostigma, Lutjanus quinquelineatus and Lethrinus sp. 2 (undescribed species: see Carpenter \& Allen 1989).

Most fishes displayed strong location fidelity, with around $60 \%$ ( $\mathrm{n}=$ 209) of total recaptures being within the same $50 \times 30 \mathrm{~m}$ block in which they were first captured (Fig. 3). There was no significant difference in the distances moved among sites (gears pooled, $\chi^{2}=7.164$, $\mathrm{df}=6, \mathrm{p}=0.306$ ). Only $13 \%(n=45)$ of all tagged fishes were recaptured at distances $>50 \mathrm{~m}$ from the position of initial capture (Fig. 3). Nevertheless, movements up to the maximum of $250 \mathrm{~m}$ were detected. However, these accounted for only $1 \%(\mathrm{n}=3)$ of all movements recorded, and were confined to Plectropomus leopardus and Lethrinus sp. 2. Comparison of the 2 fishing gears in terms of estimates of distances moved

\section{RESULTS}

A total of 1374 fishes, comprising 31 species of serranids, lutjanids and lethrinids, were tagged between 1997 and 1999, with 803 fishes tagged during the 1997 and 1998 baseline period, and 571 tagged during the 1999 manipulation period. The total number of recapture events during 1999 was 347, consisting of 17 species with a total of 1302 initially tagged specimens (Table 1). This represents a recapture rate of over $25 \%$ for the 3 target groups. The number of recaptures (Table 1) was relatively consistent among sites, with Chinamans having the highest number of recaptures ( $\mathrm{n}=100$ ), and North Point the lowest ( $\mathrm{n}=59$ ). Hook-and-line fishing accounted for more recaptures ( $\mathrm{n}=214$ ) than traps $(\mathrm{n}=133)$. This was due to the higher catch rates of the target species by hook-andline (S.L.S., D.Z. \& G.R.R. unpubl. data), rather than selective avoidance of traps by tagged fishes, as some individuals were recaptured in traps as many as 5 times.

The taxonomic composition of recaptured fishes varied between sites (Table 1). At Backreef, 4 species, Plectropomus leopardus, Cephalopholis cyanostigma, Lutjanus carponotatus, and Lethrinus atkinsoni, ac- for all sites combined indicated that there was no difference between trap and hook-and-line recaptures $\left(\chi^{2}=2.657, \mathrm{df}=2, \mathrm{p}=0.656\right)$. There were no movements recorded between any of the 4 sites for any species.

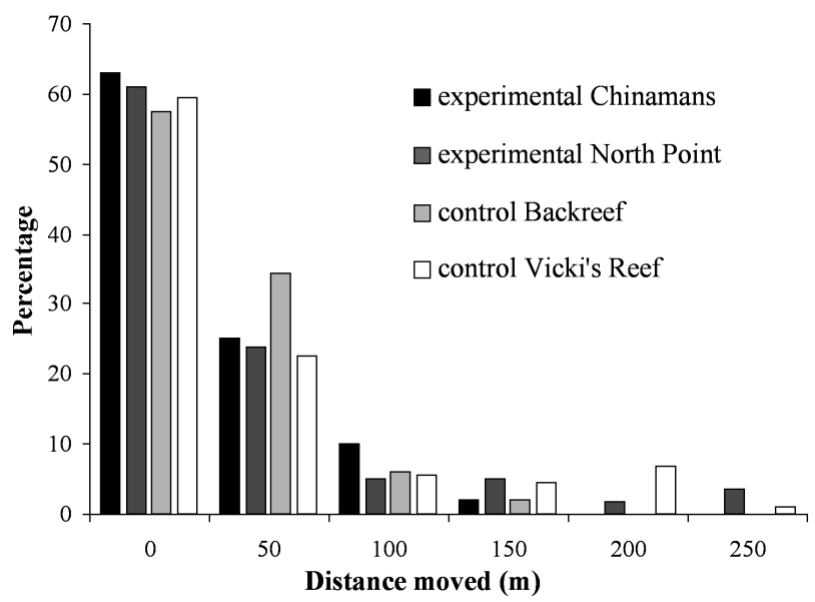

Fig. 3. Percentage of movements of all species (pooled) detected at all sites during the study; results for both fishing gears pooled. $(\mathrm{n}=100$, Chinamans; 59, North Point; 99, Backreef; 89, Vicki's Reef). 0 distance moved: fish did not move out of $50 \times 30 \mathrm{~m}$ area in which it was tagged 
The 3 species Plectropomus leopardus, Cephalopholis cyanostigma and Lutjanus carponotatus dominated recaptures and hence observed-movement data, thus we focus our species-specific presentation on these species. Distances moved by the 3 species were consistent with the overall pattern (Fig. 3), with a rapid decline in the proportion of movements $>50 \mathrm{~m}$. However, the distribution of distances moved differed significantly between the 3 species $\left(\chi^{2}=30.812\right.$, df $=4$, $\mathrm{p}=0.00)$. P. leopardus showed a greater propensity to move distances $>50$ m compared to the other 2 species, and its movements ranged widely. It was as likely to move $>50 \mathrm{~m}(40 \%)$ as not at all $(42 \%)$, and at times $(20 \%)$ moved greater distances $(>100 \mathrm{~m})$. The distances moved by C. cyanostigma differed from those of $P$. leopardus, with movements rarely recorded beyond $50 \mathrm{~m}$, and $80 \%$ of all recaptures occurring within the same $50 \times 30 \mathrm{~m}$ block of first capture. Like P. leopardus, L. carponotatus showed a propensity to move distances $>50 \mathrm{~m}$; however, its movements beyond $100 \mathrm{~m}$ were infrequent. There was no clear relationship for any of these 3 species between distance moved and time at liberty.

Underwater visual census revealed that, prior to manipulations, density gradients between zones were
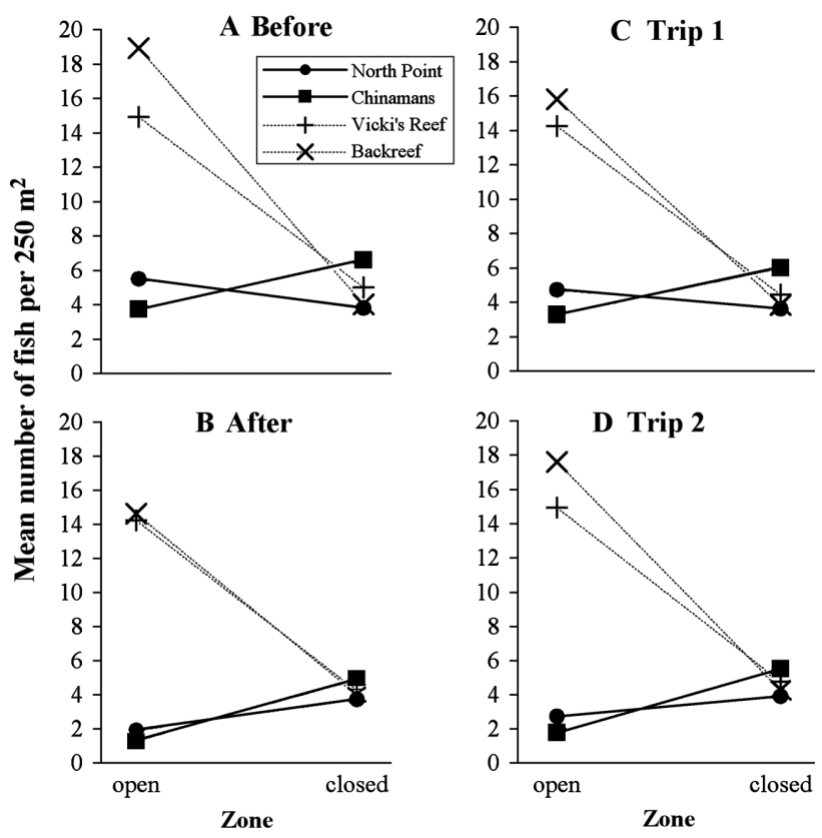

Fig. 4. Patterns of mean density (mean number of fishes $250 \mathrm{~m}^{-2}, \mathrm{n}=1104$ census counts of $50 \times 5 \mathrm{~m}$ ) observed by underwater visual census for the 2 significant highest-order ANOVA interaction terms (Table 2). Site $\times$ Zone $\times$ Time $(A, B)$ and Trip $\times$ Site $\times$ Zone $(C, D)$, illustrating gradients of density between open and closed zones at experimental (continuous lines) and control (arbitrary boundaries, dotted lines) sites before and after manipulations (A, B) and for first and second sampling periods $(C, D)$ in 1999
Table 2. Results of 4 -factor analysis of variance of underwater visual census density data for 1999 ( $\mathrm{n}=1104$ census counts of $50 \times 5 \mathrm{~m}$ ). Trip: first and second manipulation; Site: 2 experimental and 2 control sites; Zone: areas open and closed to fishing; Time: before and after each manipulation. Data log-transformed, ns: not significant at 0.05 level, ${ }^{*} \mathrm{p} \leq 0.05$, ${ }^{* *} \mathrm{p} \leq 0.01,{ }^{* * *} \mathrm{p} \leq 0.001$

\begin{tabular}{|lcccc|}
\hline Source & df & Mean square & $F$ & $\mathrm{p}$ \\
\hline Trip & 1 & 0.082 & 0.776 & $\mathrm{~ns}$ \\
Site & 3 & 5.068 & 44.594 & ${ }^{* * *}$ \\
Zone & 1 & 2.149 & 18.909 & ${ }^{* * *}$ \\
Time & 1 & 3.091 & 27.194 & ${ }^{* * *}$ \\
Trip $\times$ Site & 3 & 0.537 & 4.727 & ${ }^{* *}$ \\
Trip $\times$ Zone & 1 & 0.740 & 6.511 & ${ }^{*}$ \\
Site $\times$ Zone & 3 & 7.914 & 69.635 & ${ }^{* * *}$ \\
Trip $\times$ Site $\times$ Zone & 3 & 0.402 & 3.537 & ${ }^{*}$ \\
Trip $\times$ Time & 1 & 0.084 & 0.735 & $\mathrm{~ns}$ \\
Site $\times$ Time & 3 & 0.463 & 4.077 & ${ }^{* *}$ \\
Trip $\times$ Site $\times$ Time & 3 & 0.041 & 0.361 & $\mathrm{~ns}$ \\
Zone $\times$ Time & 1 & 0.517 & 4.545 & ${ }^{*}$ \\
Trip $\times$ Zone $\times$ Time & 1 & 0.002 & 0.018 & $\mathrm{~ns}$ \\
Site $\times$ Zone $\times$ Time & 3 & 0.359 & 3.162 & ${ }^{*}$ \\
Trip $\times$ Site $\times$ Zone $\times$ Time & 3 & 0.025 & 0.221 & $\mathrm{~ns}$ \\
Residual & 1072 & 0.114 & & \\
& & & & \\
\hline
\end{tabular}

weak at the real boundaries (experimental sites), but strong at the arbitrary control boundaries (Site $\times$ Zone $\times$ Time interaction: Table 2, Fig. 4A). We removed a total of 186 fishes from the 2 experimental $150 \times 30 \mathrm{~m}$ zones open to fishing during the 2 manipulations, significantly reducing densities (Site $\times$ Zone $\times$ Time interaction: Table 2, Fig. 4B) by 61 to $64 \%$ after the first manipulation, and by 57 to $83 \%$ after the second manipulation. The significant decline in density in experimental sites was more evident during the second manipulation period than the first manipulation period (Trip $\times$ Site $\times$ Zone interaction: Table 2, Fig. 4C,D). The patterns of density between zones did not change at the control sites, with consistently higher mean densities in the (arbitrary) 'open' zones, which in reality were not open to fishing (Fig. 4).

Only after the second manipulation was an increase in the propensity to move $50 \mathrm{~m}$ noted at the 2 experimental sites (Fig. 5A,B) compared to the control sites (Fig. 5C,D). However, pre- and post-manipulation distances did not differ statistically at any site (Pearsons chi-square $=0.405$ to $3.290 ; \mathrm{df}=2 ; \mathrm{p}=0.193$ to 0.865 ) . The increased movements at the 2 experimental sites, particularly after the second manipulation, were attributable primarily to changes in the movements of $\mathrm{Ce}$ phalopholis cyanostigma, Lutjanus carponotatus and L. quinquelineatus.

Despite the increased tendency for movement following manipulation at the 2 experimental sites (Fig. 5A,B), there was no evidence of directional movements indicating spillover. The total movements across reserve or 

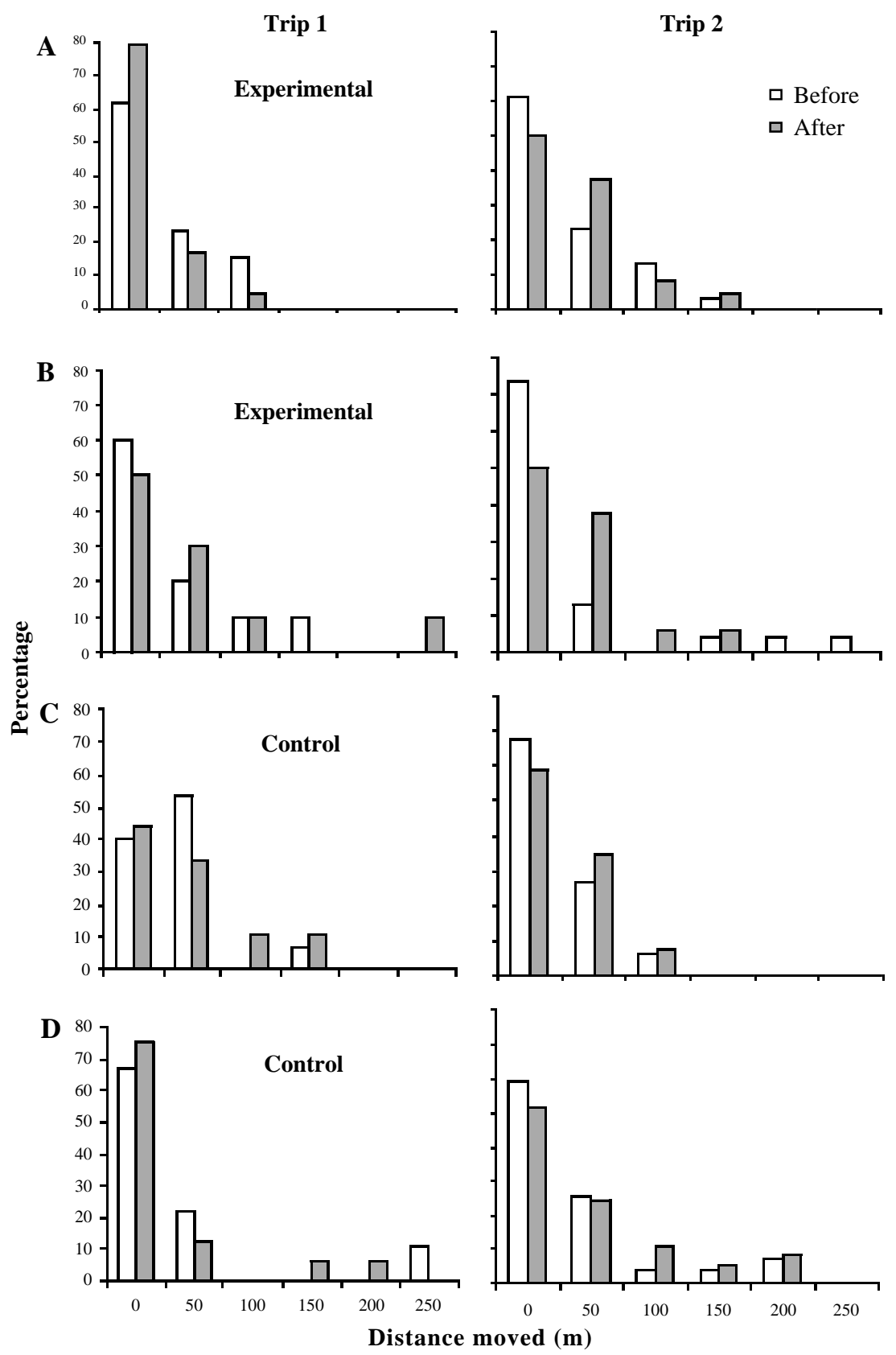

Fig. 5. Percentage of movements of all species pooled detected before (white bars) and after (grey bars) each manipulation at (A) Chinamans experimental site, (B) North Point experimental site, (C) Backreef control site and (D) Vicki's Reef control site. Sample size for Manipulations 1 and 2: (A) 32,64; (B) 22, 40; (C) 24, 75; (D) 25, 64, respectively

arbitrary control boundaries were few (total $\mathrm{n}$ for all sites $=49$ out of 347 recaptures). Fishes which had crossed boundaries constituted between 4 and $31 \%$ of all recaptures at any particular site and time. The highest proportion $(45 \%)$ of boundary crossings were movements from the adjacent $50 \mathrm{~m}$ block (Table 3). This pattern was consistent across experimental as well as control sites (Table 3). There were no clear patterns in the direction of movements (from open to closed zones or from closed to open zones) across either the reserve or arbitrary control boundaries, before and after both manipulations.

\section{DISCUSSION}

Two important expectations of marine reserves as fisheries management tools are the protection of spawning-stock biomass, thus enhancing recruitment to fisheries, and the maintenance of adjacent fisheries through spillover (Russ 2002). Although there is growing support for the use of marine reserves in the management of fisheries (Roberts et al. 2001, Russ \& Zeller 2003), there is very limited evidence upon which to assess marine reserves as a fisheries management tool, and few studies have measured the flux rates of fishes across reserve boundaries (Russ 2002). Using a rigorous experimental protocol, the present study examined the effects of manipulating density gradients on the transfer rates of fishes across 2 marine reserve boundaries to evaluate the potential for spillover.

Reef-fish movements across the 2 reserve boundaries at the experimental sites were relatively rare events. As a result, assessing the frequency and direction of movements across reserve boundaries was difficult. In contrast, Zeller \& Russ (1998), using ultrasonic tracking, demonstrated that individual Plectropomus leopardus with their home ranges at reserve boundaries moved between reserve and non-reserve habitats on average once every $2 \mathrm{~d}$. However, in the same study, mark-releaserecapture techniques did not detect boundary crossings by any of 93 marked individuals, and it was suggested that the lack of concentrated tagging and resighting effort close to the boundary was responsible for the failure to detect boundary crossings (Zeller \& Russ 1998). Therefore, we attempted to maximize detection rates by restricting tagging and recapture effort to $150 \mathrm{~m}$ either side of the boundaries. Consequently, our results indicate that $P$. leopardus were not responding to the 
Table 3. Number of recaptures and distance moved by fishes that crossed a boundary at true reserve and arbitrary control boundaries. na: not applicable, as this site had only five $50 \mathrm{~m}$ blocks, thus maximum distance that could be

\begin{tabular}{|lcccccc|}
\hline \multirow{2}{*}{ Site } & \multicolumn{6}{c|}{ Distance moved to cross boundary } \\
& $50 \mathrm{~m}$ & $100 \mathrm{~m}$ & $150 \mathrm{~m}$ & $200 \mathrm{~m}$ & $250 \mathrm{~m}$ & Total \\
\hline $\begin{array}{l}\text { Experimental } \\
\text { Chinamans }\end{array}$ & 4 & 4 & 1 & 0 & na & 9 \\
$\quad$ North Point & 7 & 0 & 2 & 1 & 2 & 12 \\
Control & 6 & 3 & 1 & 0 & 0 & 10 \\
$\quad$ Backreef & 5 & 3 & 3 & 6 & 1 & 18 \\
Vicki's Reef & 22 & 10 & 7 & 7 & 3 & 49 \\
Total number & 45 & 20 & 14 & 14 & 6 & \\
\% of total & & & & & & \\
\hline
\end{tabular}
detected was $200 \mathrm{~m}$

\& Kramer 2000). The present study supports this, with almost $60 \%$ of all recaptures occurring within the same $50 \times 30 \mathrm{~m}$ area of first capture. An important implication of limited mobility is an increased susceptibility to localized depletion (Jennings \& Kaiser 1998). Such localized depletion is already evident for some reef-fish stocks on the Great Barrier Reef (Mapstone et al. 1996). Given that reef fishes are generally long-lived and slow-growing (Ferreira \& Russ 1994), with highly variable and unpredictable recruitment events, recovery from such declines in density may take up to 10

manipulated density gradient, at least not within the post-manipulation time-frame of our study ( 3 mo).

A factor that may have influenced the movements of fishes at the manipulated reserve boundaries could be the response to the threat of the diver-based experimental manipulation (spearing). Diver-related effects on fish behaviour have been discussed in the literature (Brock 1982, Kulbicki 1998). It is possible that the spearing process may have deterred movement into the manipulated areas. Effects of spearing on the behaviour of fishes has been documented, including increases in diver avoidance and 'shyness' (Bohnsack 1998b). Similar responses were also observed in the present study (G.R.R. and D.Z. pers. obs.). The UVC abundance after manipulation (total for both experimental open zones for both manipulations, $\mathrm{n}=232$ fishes) was lower than the difference between premanipulation census numbers $(\mathrm{n}=663)$ and the number of fishes removed by spearing $(n=186)$. This suggests either some movement away from the manipulated sites, or increased diver avoidance after the manipulations. The increase in the propensity to move that was detected at the Chinamans and North Point experimental sites after the second manipulation provides some evidence to support the suggestion of movement away from sites, although the increase in movement detected was in both open and closed zones. It could be hypothesized that fishes in the closed zones at the experimental sites may have been responding to the disturbance caused by the nearby spearing activity. Therefore, interpretation of the apparent increase in movement after the second manipulation is difficult.

The extent to which a marine reserve will be able to sustain the export of post-settlement biomass will depend on the rates of recruitment, growth and also the rate of transfer out of the reserve. It has been widely acknowledged that reef fish show strong site-fidelity (Sale 1991, Samoilys 1997, Zeller 1997, 2002, Chapman to 15 yr (Russ \& Alcala 1996b, Jennings \& Kaiser 1998, Russ \& Alcala 1998). Modelling studies suggest that highly mobile species may cross reserve boundaries frequently, and be exposed to adjacent fisheries. This may negate the potential biomass accumulation within a reserve (Polacheck 1990, DeMartini 1993, Russ et al. 1993). Species-specific differences in the propensity to move, and the distances moved, were demonstrated in the present study. The tendency for Plectropomus leopardus to move distances greater than $100 \mathrm{~m}$ suggests that this species may not benefit as much from small-scale closures within reefs as would less mobile species. Extensive within-reef movements over small distances (10s to 100 s of metres) have been documented for this species (Davies 1995, Samoilys 1997, Zeller 1997, 1998, 2002). In contrast, the more limited movements of Cepaholpholis cyanostigma and Lutjanus carponotatus suggest that small marine reserves may serve to effectively protect these species. These patterns of movement are consistent with the body size and feeding behaviour of these 3 species. Based on the limited movements of most reef fishes, the migration of post-settlement fishes to exploited habitats is unlikely to contribute significantly to any stock recoveries in areas other than those close to the reserves. Replenishment of these areas will be dependent largely on recruitment supply. Thus, the long-term benefits of marine reserves to overall stock densities may depend on their ability to enhance larval supply to exploited fisheries through maintenance or rebuilding of spawning stock biomass, rather than their ability to export post-settlement biomass. Despite this, spillover remains of great significance in gaining local community support for successful marine reserves (Russ \& Alcala 1996b, Roberts et al. 2001).

We could detect movements only within the $300 \times$ $30 \mathrm{~m}$ sites. Thus, we could not detect distances moved $>250 \mathrm{~m}$. Furthermore, we could not account for fishes which moved laterally $>30 \mathrm{~m}$ across the sides of 
the study sites. Clearly, more active species, such as lethrinids had a reduced likelihood of being recaptured within our study area, as exemplified by Lethrinus sp. 2, with only 13 recaptures out of 234 tagged specimens (Table 1). Our study sites were designed to target obligatory reef fishes of major fisheries importance such as coral trout Plectropomus leopardus and other serranids (e.g. Cephalopholis spp.), and small lutjanids which are known to have more limited ranges of movements (Roberts \& Polunin 1991, Samoilys 1997, Zeller 1997, Zeller \& Russ 1998, O'Dor et al. 2001). Previous movement studies, which have distributed tagging and recapture effort over larger spatial scales, have demonstrated similar patterns of distances moved. Zeller \& Russ (1998) reported that the average distance moved by $P$. leopardus between resightings was $35 \mathrm{~m}$. This previous study had the potential to detect larger-scale movements, since the sampling area was $154000 \mathrm{~m}^{2}$, spread extensively around Lizard Island. Similarly, in a tagging study by Beinssen (1989), only $7 \%$ of $P$. leopardus recaptures at Heron Island, Australia, had travelled distances greater than $500 \mathrm{~m}$. The overall recapture rate of $>25 \%$ of target species observed in the present study compares well with similar studies undertaken on the GBR using the same trapping technique (Davies 1989). Davies reported recapture rates of 21 and $43 \%$ for Plectropomus spp. and Lutjanus carponotatus, respectively. In the present study, high recapture rates, a high proportion of 'zero' movements, and the failure to detect an association between time at liberty and distance moved, suggest that the movements detected were a reliable representation of movements within sites.

This study provides a basis for future experimental studies attempting to quantify spillover from marine reserves to nearby areas. Unlike previous studies, our sampling protocol quantified the distance and direction of movement across reserve boundaries and therefore could detect spillover. Surprisingly, virtually no study in the mainstream literature has previously attempted this (Russ 2002). The study also demonstrated that very high levels of sampling effort may be required to have sufficient power to detect changes in movement. The role of density-dependent processes in facilitating net export could not be determined conclusively in the present study. Gradients in density were present at the experimental reserve boundaries at Lizard Island only after the second manipulation. Fishing pressure at Lizard Island is considered light (Zeller \& Russ 1998). Furthermore, large density gradients were evident at the arbitrary boundaries at the non-fished control sites. These patterns may reflect differences in habitat suitability (Jones 1991, Rakitin \& Kramer 1996). Unfortunately, longer term responses to the manipulation (i.e. longer than the 3 mo period between manipulations) could not be assessed in this study. Alternatively, the experimental reductions in densities in the open zones may not have been sufficient to facilitate a response by conspecifics in the adjacent closed zones. A better understanding of the influences of density variations on movement patterns are essential to predicting how such processes may affect reserve function. Nevertheless, this study is the first to manipulate density gradients at reserve boundaries and measure the effects on movement patterns of reef fishes. It thus provides essential baseline information for future research (Russ 2002). Detection of spillover in future studies will require powerful sampling protocols, incorporating stronger density gradients across large numbers of reserve boundaries, and substantial numbers of tagged fishes, monitored over long time periods.

Although this study could not unequivocally establish the effects of manipulating density gradients on spillover, the movements recorded indicate the likely scale of spillover. It was shown that the movement patterns of species primarily targeted by commercial and recreational fisheries (particularly serranids and small lutjanids) were restricted; few fishes moved distances greater than $150 \mathrm{~m}$. If spillover were to occur, the benefits of higher catch rates in the local fisheries might occur on the scale of 10 s to 100 s of metres, on a scale similar to that demonstrated for small reserves in the Philippines (Alcala \& Russ 1990, Russ \& Alcala 1996b) and elsewhere (Roberts et al. 2001).

Acknowledgements. We would like to thank A. Hoey, G. Poy and numerous volunteers for assistance with field work, and the staff at Lizard Island Research Station for their support throughout this project. In particular we would like to thank G. Carlos and J. Kritzer for assistance with the manipulations. We gratefully acknowledge support of an Australian Research Council Large Research Grant, and thank the School of Marine Biology and Aquaculture, James Cook University, for logistic support. The comments of 3 anonymous reviewers greatly improved the manuscript.

\section{LITERATURE CITED}

Alcala AC, Russ GR (1990) A direct test of the effects of protective management on abundance and yield of tropical marine resources. J Cons Int Explor Mer 46:40-47

Attwood CG, Bennett BA (1994) Variation in dispersal of galjoen (Coracinus capensis) (Teleostei: Coracinidae) from a marine reserve. Can J Fish Aquat Sci 51:1247-1257

Attwood CG, Bennett BA (1995) Modelling the effect of marine reserves on the recreational shore-fishery of the south-western Cape, South Africa. S Afr J Mar Sci 16: 227-240

Barrett NS (1995) Short- and long-term movement patterns of six temperate reef fishes (families Labridae and Monacanthidae). Mar Freshw Res 46:853-860

Beinssen K (1989) Results of the Boult Reef replenishment area study. Final report, Report of the Department of Conservation, Parks and Wildlife, Rockhampton 
Beinssen P, Beinssen K (1991) Heron Island reef fish movement study. Report of the Department of Conservation, Parks and Wildlife, Rockhampton, Australia

Bell JD, Craik GJS, Pollard DA, Russell BC (1985) Estimating length frequency distributions of large reef fish underwater. Coral Reefs 4:41-44

Beverton RJH, Holt SJ (1957) On the dynamics of exploited fish populations. Fish Investig Ser II, Mar Fish GB Minist Agric Fish Food 19:1-533

Bohnsack JA (1998a) Application of marine reserves to fisheries management. Aust J Ecol 23:298-304

Bohnsack JA (1998b) Reef fish response to divers in two 'notake' marine reserves in Hawaii. Reef Encounter 23:22-24

Brock RE (1982) A critique of the visual census method for assessing coral reef fish populations. Bull Mar Sci 32:269-276

Buechner M (1987) Conservation in insular parks: simulation models of factors affecting the movement of animals across park boundaries. Biol Conserv 41:57-76

Carpenter KE, Allen GR (1989) FAO species catalogue, Vol 9. Emperor fishes and large-eyed breams of the world. Food and Agricultural Organization of the United Nations, Rome

Carpenter KE, Miclat RI, Albaladejo VD, Corpuz VT (1981) The influence of substrate structure on the local abundance and diversity of Philippine reef fishes. Proc 4th Int Coral Reef Symp Quezon City, p 497-502

Chapman MR, Kramer DL (1999) Gradients in coral reef fish density and size across the Barbados marine reserve boundary: effects of reserve protection and habitat characteristics. Mar Ecol Prog Ser 181:81-96

Chapman MR, Kramer DL (2000) Movements of fishes within and among fringing coral reefs in Barbados. Environ Biol Fish 57:11-24

Choat JH, Bellwood DR (1985) Interactions amongst herbivorous fishes on a coral reef: influence of spatial variation. Mar Biol 89:221-234

Cochran WG (1954) Some methods for strengthening the common chi-square tests. Biometrics 10:417-451

Davies CR (1989) The effectiveness of non-destructive sampling of coral reef fish populations with fish traps. Honours thesis, James Cook University, Townsville

Davies CR (1995) Patterns of movement of three species of coral reef fish on the Great Barrier Reef. PhD thesis, James Cook University, Townsville

Davis GE, Dodrill JW (1989) Recreational fishery and population dynamics of spiny lobsters, Panulirus argus, in Florida Bay, Everglades National Park, 1977-1980. Bull Mar Sci 44:78-88

DeMartini EE (1993) Modeling the potential of fishery reserves for managing Pacific coral reef fishes. Fish Bull US Fish Wildl Serv 91:414-427

Eggers DM, Rickard NA, Chapman DG, Whitman RR (1982) A methodology for estimating area fished for baited hooks and traps along a ground line. Can J Fish Aquat Sci 39: 448-453

Ferreira BP, Russ GR (1994) Age validation and estimation of growth-rate of a tropical serranid, the coral trout Plectropomus leopardus (Lacepede 1802) from Lizard Island, Northern Great Barrier Reef. Fish Bull US Fish Wildl Serv 92:46-57

Funicelli NA, Meineke DA, Bryant HE, Dewey MR, Ludwig GM, Mengel LS (1989) Movements of striped mullet, Mugil cephalus, tagged in Everglades National Park, Florida. Bull Mar Sci 44:171-178

Jennings S, Kaiser MJ (1998) The effects of fishing on marine ecosystems. Adv Mar Biol 34:1-70

Jones GP (1991) Postrecruitment processes in the ecology of coral reef fish populations: a multifactorial perspective. In:
Sale PF (ed) The ecology of fishes on coral reefs. Academic Press, San Diego, p 294-328

Kulbicki M (1998) How the acquired behaviour of commercial reef fishes may influence the results obtained from visual censuses. J Exp Mar Biol Ecol 222:11-30

Leis JM (1991) The pelagic stage of reef fishes: the larval biology of coral reef fishes. In: Sale PF (ed) The ecology of fishes on coral reefs. Academic Press, San Diego, p 183-227

Mapstone BD, McKinlay JP, Davies CR (1996) A description of the commercial reef line fishery logbook data held by the Queensland Fisheries Management Authority: report to the Queensland Fisheries Management Authority from the Co-operative Research Centre for the Ecologically Sustainable Development of the Great Barrier Reef, and the Department of Tropical Environmental Studies and Geography, James Cook University, Townsville

McClanahan TR, Mangi S (2000) Spillover of exploitable fishes from a marine park and its effect on the adjacent fishery. Ecol Appl 10:1792-1805

Munro JL (1983) The composition and magnitude of trap catches in Jamaican waters. In: Munro JL (ed) Caribbean coral reef fishery resources. International Center for Living Aquatic Resources Management (ICLARM), Manila, p 33-49

Newman SJ (1990) Effects of depth set, mesh size, bait and lunar phase on the performance of fish traps on the Great Barrier Reef. Honours thesis, James Cook University, Townsville

O'Dor RK, Aitken JP, Bolden S, Babcock RC, Seinto S, Zeller DC, Jackson G (2001) Using radio-acoustic positioning and telemetry (RAPT) to define and assess marine protected areas (MPAs). In: Siebert JR, Nielsen JR (eds) Electronic tagging and tracking in marine fisheries. Kluwer Academic Publishers, Dordrecht, p 147-166

PDT (Plan Development Team) (1990) The potential of marine fishery reserves for reef fish management in the US Southern Atlantic, NOAA Tech Memo NMFSSEFC-261

Polacheck T (1990) Year round closed areas as a management tool. Nat Res Model 4:327-354

Rakitin A, Kramer DL (1996) Effect of a marine reserve on the distribution of coral reef fishes in Barbados. Mar Ecol Prog Ser 131:97-113

Randall JE, Allen GR, Steene RC (1997) Fishes of the Great Barrier Reef and Coral Sea, Vol 1. Crawford House, Bathurst, Australia

Roberts C, Polunin NVC (1991) Are marine reserves effective in management of reef fisheries? Rev Fish Biol Fish 1: 65-91

Roberts C, Polunin NVC (1993) Marine reserves: simple solutions to managing complex fisheries? Ambio 22:363-368

Roberts C, Bohnsack JA, Gell F, Hawkins JP, Goodridge R (2001) Effects of marine reserves on adjacent fisheries. Science 294:1920-1923

Rowley RJ (1994) Marine reserves in fisheries management. Aquat Conserv 4:233-254

Russ GR (1991) Coral reef fisheries: effects and yields. In: Sale PF (ed) The ecology of fishes on coral reefs. Academic Press, San Diego, p 601-635

Russ GR (2002) Yet another review of marine reserves as reef fisheries management tools. In: Sale PF (ed) Coral reef fishes: dynamics and diversity in a complex ecosystem. Academic Press, San Diego, p 421-443

Russ GR, Alcala AC (1996a) Do marine reserves export adult fish biomass? Evidence from Apo Island, central Philippines. Mar Ecol Prog Ser 132:1-9

Russ GR, Alcala AC (1996b) Marine reserves: rates and 
patterns of recovery and decline of large predatory fish. Ecol Appl 6:947-961

Russ GR, Alcala AC (1998) Natural fishing experiments in marine reserves 1983-1993: community and trophic responses. Coral Reefs 17:383-397

Russ GR, Zeller D (2003) From mare liberum to mare reservarum. Mar Policy 27:75-78

Russ GR, Alcala AC, Cabanban AS (1993) Marine reserves and fisheries management on coral reefs with preliminary modelling of the effects on yield per recruit Proc 7 th Int Coral Reef Symp, Mangilao, p 988-995

Sale PF (1991) The ecology of fishes on coral reefs, Vol 1. Academic Press, San Diego

Samoilys MA (1997) Movement in a large predatory fish: coral trout, Plectropomus leopardus (Pisces: Serranidae), on Heron Island, Australia. Coral Reefs 16:151-158

Underwood AJ (1994) On beyond BACI: sampling designs that might reliably detect environmental disturbances. Ecol Appl 4:3-15

Walters C, Pauly D, Christensen V (1999) Ecospace: predic-

Editorial responsibility: Otto Kinne (Editor),

Oldendorf/Luhe, Germany tion of mesoscale spatial patterns in trophic relationships of exploited ecosystems, with emphasis on the impacts of marine protected areas. Ecosystems 2:539-554

Yamasaki A, Kuwahara A (1990) Preserved area to effect recovery of overfished Zuwai crab stocks off Kyoto Prefecture. Proc Int Symp King and tanner crabs. Alaska Sea Grant College Program, University of Alaska, Fairbanks, p 575-578

Zeller D (1997) Home range and activity patterns of the coral trout Plectropomus leopardus (Serranidae). Mar Ecol Prog Ser 154:65-77

Zeller D (1998) Spawning aggregations: patterns of movement of the coral trout Plectropomus leopardus (Serranidae) as determined by ultrasonic telemetry. Mar Ecol Prog Ser 162:253-263

Zeller D (2002) Tidal current orientation of Plectropomus leopardus (Serranidae). Coral Reefs 21:183-187

Zeller D, Russ GR (1998) Marine reserves: patterns of adult movement of the coral trout Plectropomus leopardus (Serranidae). Can J Fish Aquat Sci 55:917-924

Submitted: March 5, 2002; Accepted: January 7, 2003

Proofs received from author(s): May 12, 2003 